\title{
Molecular Mapping of Loci Conferring Susceptibility to Spot Blotch and Resistance to Powdery Mildew in Barley Using the Sequencing-Based Genotyping Approach
}

\author{
Yueqiang Leng, ${ }^{1}$ Mingxia Zhao, ${ }^{1}$ Jason Fiedler, ${ }^{2,3}$ Antonín Dreiseitl, ${ }^{4}$ Shiaoman Chao, ${ }^{3}$ Xuehui Li, ${ }^{2}$ and Shaobin Zhong $1, \dagger$ \\ ${ }^{1}$ Department of Plant Pathology, North Dakota State University, Fargo, ND 58102, U.S.A. \\ ${ }^{2}$ Department of Plant Science, North Dakota State University, Fargo, ND 58102, U.S.A. \\ ${ }^{3}$ U.S. Department of Agriculture-Agriculture Research Service Cereal Crops Research Unit, Fargo, ND 58102, U.S.A. \\ ${ }^{4}$ Agrotest Fyto Ltd., Kroměříž, Czech Republic \\ Accepted for publication 5 October 2019.
}

\begin{abstract}
Spot blotch (SB) caused by Bipolaris sorokiniana and powdery mildew (PM) caused by Blumeria graminis f. sp. hordei are two important diseases of barley. To map genetic loci controlling susceptibility and resistance to these diseases, a mapping population consisting of 138 recombinant inbred lines (RILs) was developed from the cross between Bowman and ND5883. A genetic map was constructed for the population with 852 unique single nucleotide polymorphism markers generated by sequencing-based genotyping. Bowman and ND5883 showed distinct infection responses at the seedling stage to two isolates (ND90Pr and $\mathrm{ND} 85 \mathrm{~F}$ ) of Bipolaris sorokiniana and one isolate (Race I) of Blumeria graminis f. sp. hordei. Genetic analysis of the RILs revealed that one major gene ( $\operatorname{Scs} 6)$ controls susceptibility to Bipolaris sorokiniana iso-

mapped on chromosome $1 \mathrm{H}$ of Bowman, as previously reported. Mla 8 was also mapped to the short arm of $1 \mathrm{H}$, which was tightly linked but not allelic to the Rcs6/Scs6 locus. Quantitative trait locus (QTL) analysis identified two QTLs, $Q S b s-1 H-P 1$ and $Q S b s-7 H-P 1$, responsible for susceptibility to spot blotch caused by Bipolaris sorokiniana isolate ND85F in ND5883, which are located on chromosome $1 \mathrm{H}$ and $7 \mathrm{H}$, respectively. QSbs-7H-P1 was mapped to the same region as Rcs5, whereas $Q S b s-1 H-P 1$ may represent a novel allele conferring seedling stage susceptibility to isolate ND85F. Identification and molecular mapping of the loci for SB susceptibility and PM resistance will facilitate development of barley cultivars with resistance to the diseases.
\end{abstract} late ND90Pr, and another major gene (Mla8) confers resistance to Blumeria graminis f. sp. hordei isolate Race I, respectively. Scs6 was
Keywords: genetics and resistance
Spot blotch (SB) and powdery mildew (PM) of barley are caused by Bipolaris sorokiniana (syn. Cochliobolus sativus) and Blumeria graminis f. sp. hordei, respectively. These two fungal pathogens have different lifestyles. Bipolaris sorokiniana is considered hemibiotrophic (Kumar et al. 2002), whereas Blumeria graminis f. sp. hordei is biotrophic (Both and Spanu 2004). Epidemics of the two diseases can significantly reduce yield and quality of the crop. SB occurs mainly in North America, especially in the northern Great Plains of the United States and Canadian prairies, and 33\% of yield loss has been reported for the disease (Mathre 1997; Wilcoxson et al. 1990). PM is commonly observed in almost all regions of the world where barley is grown; it is the most prevalent barley disease in Europe (Dreiseitl 2011; Jørgensen 1994) and the second most important disease in Australia, with the potential to reduce annual production by $\$ 103$ million (Murray and Brennan 2010). Yield losses to PM range from 5 to $20 \%$ and reach $40 \%$ under favorable conditions (Chaure et al. 2000). Use of host resistance is the most effective method for managing these two important diseases.

In the past several decades, a number of resistance sources for SB have been identified, and major genes and quantitative trait loci (QTLs) for resistance to the disease have been mapped. For

${ }^{\dagger}$ Corresponding author: S. Zhong; shaobin.zhong@ndsu.edu

*The $\boldsymbol{e}$-Xtra logo stands for "electronic extra" and indicates that one supplementary figure and three supplementary tables are published online.

The author(s) declare no conflict of interest.

(c) 2020 The American Phytopathological Society example, Steffenson et al. (1996) and Bilgic et al. (2005) identified a gene (Rcs5) on chromosome $7 \mathrm{H}$ conferring seedling SB resistance to pathotype $1(\mathrm{ND} 85 \mathrm{~F})$ of Bipolaris sorokiniana by using a doubled haploid (DH) population derived from the cross between Steptoe and Morex. Further studies indicated that $R \operatorname{cs} 5$ is a recessive allele for resistance to SB, and it is the dominant allele at the same locus that confers susceptibility to the disease (Ameen 2019). Bilgic et al. (2006) identified a gene (designated as $R \operatorname{cs} 6$ ) on chromosome $1 \mathrm{H}$ conferring resistance to pathotype 2 (ND90Pr) of Bipolaris sorokiniana by using a DH population from the Calicuchima-sib/ Bowman-BC cross. Our recent study indicated that $R \operatorname{cs} 6$ is a recessive allele, and the corresponding dominant allele (designated as $S \operatorname{cs} 6$ ) at the same locus is responsible for susceptibility to pathotype 2 of Bipolaris sorokiniana in cultivar Bowman (Leng et al. 2018). Other genes or QTLs for SB resistance have been identified and mapped on different barley chromosomes (Berger et al. 2013; Bilgic et al. 2005, 2006; Bovill et al. 2010; Castro et al. 2012; Grewal et al. 2012; Wang et al. 2017, 2019; Zhou and Steffenson 2013).

For PM, a number of major resistance genes and QTLs also have been identified and reported in barley. The described major genes for PM resistance include Mla, Mlat, Mlk, Mlnn, Mlra, MlGa, and Mlp on chromosome 1H (Jørgensen 1994; Wei et al. 1999), MlLa on 2H (Jørgensen 1994), mlo and Mlg on 4H (Baker et al. 1997; Buschges et al. 1997), Mlj on 5H (Schonfeld et al. 1996), Mlh on 6H (Jørgensen 1994), and $m l t$ and Mlf on 7H (Schonfeld et al. 1996). Among them, Mla and mlo are the most effective and widely deployed PM resistance genes in barley breeding programs. Mla is a complex locus that comprises $\geq 30$ alleles with various specificities to different races of Blumeria graminis f. sp. hordei (Seeholzer et al. 2010; Wei et al. 1999). The gene mlo, which was derived from 
loss-of-function of the gene at the Mlo locus, exhibits broadspectrum resistance to Blumeria graminis f. sp. hordei and thus has been widely used in European countries to protect barley from PM for almost four decades (Büschges et al. 1997; Kusch and Panstruga 2017). However, several studies indicated that the mlo-based resistance led to more susceptibility to hemibiotrophic and necrotrophic pathogens such as Magnaporthe oryzae, Ramularia collo-cygni, and Bipolaris sorokiniana in barley (Brown and Rant 2013; Jarosch et al. 1999; Kumar et al. 2001; McGrann et al. 2014), raising the issue of trade-off between resistance to biotrophic pathogens and increased susceptibility to nonbiotrophic pathogens. In addition to the major genes, QTLs for PM resistance have been identified in wild and cultivated barley populations through genome-wide association studies (Ames et al. 2015; Bengtsson et al. 2017).

To map genes or QTLs for traits of interest in plants, a number of marker technologies have been used, including restriction fragment length polymorphisms, amplified fragment length polymorphisms, simple sequence repeats, and single nucleotide polymorphisms (SNPs). Among them, SNPs have become increasingly favored because of their abundance, relative ease of discovery, and low cost per data point (Kumar et al. 2012). To genotype SNP markers, highthroughput Illumina arrays have been developed for cereal crops, including wheat (Wang et al. 2014; Winfield et al. 2016), rice (Chen et al. 2014), maize (Ganal et al. 2011), and barley (Bayer et al. 2017; Close et al. 2009; Comadran et al. 2012; Fan et al. 2003). With the decreasing costs of sequencing, the sequencing-based genotyping (SBG) approach has become more popular. SBG has been used to construct genetic maps and identify several genes or QTLs in barley (Liu et al. 2014; Poland et al. 2012). Especially with the availability of a new barley genome assembly (Mascher et al. 2017; Monat et al. 2019), discovery of SNP markers by SBG in a mapping population and construction of marker-saturated genetic map for gene mapping have become more popular and easier.

In a previous study (Leng et al. 2018), we fine-mapped and physically anchored the dominant SB susceptibility gene Scs6 to a $125-\mathrm{kb}$ genomic region containing the Mla locus on barley chromosome $1 \mathrm{H}$ of Morex, but it is still not known whether Scs6 is allelic to any of the Mla alleles. Therefore, the objectives of this study were to identify and map loci conferring susceptibility to SB and resistance to PM in a recombinant inbred line (RIL) mapping population derived from a cross between barley cultivar Bowman and barley line ND5883 through the SBG approach, and unravel the relationship between $S c s 6$ and a gene for PM resistance at the Mla locus.

\section{MATERIALS AND METHODS}

Plant materials. A mapping population consisting of 138 RILs developed from a cross between Bowman and ND5883 were used in the study. Bowman is a two-rowed barley cultivar released by North Dakota State University (NDSU) (Franckowiak et al. 1985), which is resistant to the pathotype 1 isolate ND85F of Bipolaris sorokiniana but susceptible to the pathotype 2 isolate ND90Pr of the fungus (Valjevec-Gratian and Steffenson 1997a; Zhong and Steffenson 2001). ND5883 is an experimental barley line also released by NDSU, which is susceptible to isolate ND85F but resistant to isolate ND90Pr (Valjevec-Gratian and Steffenson 1997a; Zhong and Steffenson 2001). Bowman and ND5883 and another NDSU experimental barley line, NDB 112, are commonly used as differentials for identification of pathotypes of Bipolaris sorokiniana in North Dakota (Valjevec-Gratian and Steffenson 1997a, b; Zhong and Steffenson 2001).

SB phenotyping. The method described by Leng et al. (2016) was used to evaluate the infection responses (IRs) of the barley parents (Bowman and ND5883) and the mapping population to SB at the seedling stage. Two Bipolaris sorokiniana isolates, ND85F and ND90Pr, were used in this study. ND85F (pathotype 1) and
ND90Pr (pathotype 2) (Valjavec-Gratian and Steffenson 1997a, b; Zhong and Steffenson 2001) are routinely used in our studies on the barley-Bipolaris sorokiniana system (Leng et al. 2011; Leng and Zhong 2012, 2015; Wang et al. 2015, 2016). The isolates were grown on V8 PDA ( $150 \mathrm{ml}$ of $\mathrm{V} 8$ juice, $3 \mathrm{~g}$ of $\mathrm{CaCO}_{3}, 39 \mathrm{~g}$ of potato dextrose agar, and $850 \mathrm{ml}$ of distilled water) under $14 \mathrm{~h}$ fluorescent light each day at approximately $23^{\circ} \mathrm{C}$. After 7 days of growth, conidia were harvested, and conidial suspension was prepared for spray inoculation as described by Leng et al. (2016). The 1 to 9 rating scale of Fetch and Steffenson (1999) was used to rate the IR of each barley plant. Range of IR (minimum and maximum) and the most common IR (mode of IR) were recorded for each barley genotype, and each genotype was classified as low (with mode 1 to 3), intermediate (with mode 4 to 5), or high (with mode 6 to 9) IR. Three inoculation experiments were conducted for all barley genotypes. Mean disease rating scores were calculated for each genotype and used for further analysis.

PM evaluation. Bowman and ND5883 were initially evaluated with 50 reference Blumeria graminis f. sp. hordei isolates collected in all nonpolar continents over a period of 63 years (1953 to 2016), including an old Japanese Blumeria graminis f. sp. hordei isolate designated as Race I (Hiura and Heta 1955) to postulate their specific resistance genes against PM. Before inoculation, all Blumeria graminis f. sp. hordei isolates were checked for their purity and verified for their correct pathogenicity phenotypes on standard barley differential lines (Kølster et al. 1986). The isolates were multiplied on leaf segments of susceptible cultivar Stirling (Dreiseitl and Platz 2012). The method for PM inoculation and evaluation was previously described (Dreiseitl 2014). Briefly, 20 seeds of each parent and 5 seeds of each RIL were sown in plastic pots ( $80 \mathrm{~mm}$ diameter) filled with a gardening peat substrate and placed in a mildew spore-proof greenhouse under natural daylight. Leaf segments (15 mm long) were cut from the central part of healthy, fully expanded primary leaves when the second leaves were emerging. Three leaf segments taken from three plants of each RIL were placed with adaxial surfaces upward in a $150-\mathrm{mm}$ Petri dish on water agar $(0.8 \%)$ containing benzimidazole $(40 \mathrm{mg} / \mathrm{l})$, a leaf senescence inhibitor. In each Petri dish, leaf segments from each of the two parents (Bowman and ND5883) were placed as checks. The dishes with leaf segments were placed at the bottom of a metal inoculation tower and inoculated at a concentration of about 8 conidiospores per square millimeter. The dishes with inoculated leaf segments were incubated at $18.0 \pm 2.0^{\circ} \mathrm{C}$ under artificial light (cool-white fluorescent lamps providing $12 \mathrm{~h}$ light at $30 \pm 5 \mu \mathrm{mol} /$ $\mathrm{m}^{2} / \mathrm{s}$ ) with a 12-h photoperiod under artificial light supplied by cool-white fluorescent lamps $\left(30 \pm 5 \mu \mathrm{mol} / \mathrm{m}^{2} / \mathrm{s}\right)$. At 6 and 8 days after inoculation, IRs (phenotype of genotype $\times$ isolate interaction) on the central part of the adaxial side of leaf segments were scored on a 0 to 4 scale including intertypes, where $0=$ no mycelium and sporulation, and $4=$ strong mycelial growth and sporulation (Torp et al. 1978; Supplementary Table S1). Each genotype was tested in two independent experiments, and mean IR score was calculated for further analysis. IRs of 0 to 3 were classified as resistant, and IRs of 4 were classified as susceptible. For postulation of PM resistance genes, an IR array (IRA) was generated for each line according to its IRs to the Blumeria graminis f. sp. hordei isolates. By comparing the IRA with previously determined IRAs of standard barley differentials possessing known resistance genes, we postulated the resistance genes in each tested line based on the gene-for-gene model.

DNA extraction and construction of SBG libraries. DNAs were extracted from 2-week-old seedling plants of the parents and 138 RILs with a DNA purification kit and quantified with a fluorometer according to the manufacturers' protocols. The DNA samples were diluted and normalized at a concentration of $50 \mathrm{ng} / \mu \mathrm{l}$. The 140 samples were split into two 96-well plates, one with 72 samples and the other with 68 samples. The SBG libraries were constructed according to the methods described by Saintenac 
et al. (2013). Briefly, DNAs were digested in 30- $\mu$ l reactions containing $200 \mathrm{ng}$ of genomic DNA, $1 \times$ New England Biolabs buffer $4,8 \mathrm{U}$ of PstI-HF, and $8 \mathrm{U}$ of $M s e \mathrm{I}$, incubated at $37^{\circ} \mathrm{C}$ for $3 \mathrm{~h}$, then $80^{\circ} \mathrm{C}$ for $20 \mathrm{~min}$ to inactivate the enzymes. For ligation, $4 \mathrm{ng}$ of annealed barcoded adapter (Saintenac et al. 2013) and $200 \mathrm{ng}$ of annealed common Y-adapter (Saintenac et al. 2013) were added along with $1 \times$ T4 DNA ligase buffer and $200 \mathrm{U}$ of T4 ligase in a total volume of $50 \mu \mathrm{l}$. All ligation reactions were incubated at $22^{\circ} \mathrm{C}$ for $2 \mathrm{~h}$, then $65^{\circ} \mathrm{C}$ for $20 \mathrm{~min}$. An aliquot $(5 \mu \mathrm{l})$ was removed from each ligation reaction, pooled, purified with a PCR purification kit, and eluted in $30 \mu \mathrm{l}$ of $\mathrm{dH}_{2} \mathrm{O}$. PCR amplification was conducted in $50-\mu \mathrm{l}$ reactions containing $4 \mu \mathrm{l}$ of pooled and purified library DNA, $1 \times$ high-fidelity DNA polymerase buffer, $0.2 \mu \mathrm{M}$ of dNTP, $0.2 \mu \mathrm{M}$ of primer 1 (complementary to barcode adapter), $0.2 \mu \mathrm{M}$ of primer 2 (complementary to common Y-adapter), and $1 \mathrm{U}$ of Taq polymerase. PCR was conducted as follows: $98^{\circ} \mathrm{C}$ for 30 s for one cycle; 20 cycles of $98^{\circ} \mathrm{C}$ for $10 \mathrm{~s}, 65^{\circ} \mathrm{C}$ for $20 \mathrm{~s}$, and $68^{\circ} \mathrm{C}$ for $20 \mathrm{~s}$; and one cycle of $75^{\circ} \mathrm{C}$ for $5 \mathrm{~min}$, cool to $4^{\circ} \mathrm{C}$. The PCR-enriched library was gel purified, with the 200- to 500-bp size fraction selected with a gel extraction kit, eluted in $12 \mu \mathrm{l}$ of $\mathrm{ddH}_{2} \mathrm{O}$, and the quality and quantity of the library were measured with a spectrophotometer and bioanalyzer.

Sequencing and processing raw SBG data. Single-read sequencing from the $P s t \mathrm{I}$ site was carried out, and $150 \mathrm{bp}$ reads were generated. The two parents, Bowman and ND5883, were originally included in the library construction and sequencing, but not enough reads were generated for them. To have higher coverage for the parents, the DNA samples were sent to BGI (Cambridge, MA) for whole-genome sequencing in the BGI500 sequencing platform, where paired-end 100-bp reads were generated. All sequence reads were submitted to the Sequence Read Archive section of the NCBI (accession no. PRJNA514287).

SNP discovery and genotype calling. SNP discovery and genotype calling were performed using the TASSEL-GBS pipeline (Glaubitz et al. 2014), and the Morex genome pseudomolecule and contigs sequences (version 2.0, http://plants.ensembl.org/Hordeum_ vulgare/Info/Index) were used as the references.

Linkage map construction and QTL identification. Linkage analysis was performed in MapDisto (Lorieux 2012) with a logarithm of the odds (LOD) threshold of 3.0 and theta value of 0.4 . For cosegregating SNP markers in the mapping population, only one was selected for constructing the genetic map. Recombination fraction was converted into map distance via the Kosambi function. The genetic linkage maps were generated in MapChart version 2.1 (Voorrips 2002). QTL interval mapping was used to locate QTLs for susceptibility to SB in QGene, version 4.3.10 (Joehanes and Nelson 2008). A permutation test with 1,000 permutations was used to establish the LOD threshold.

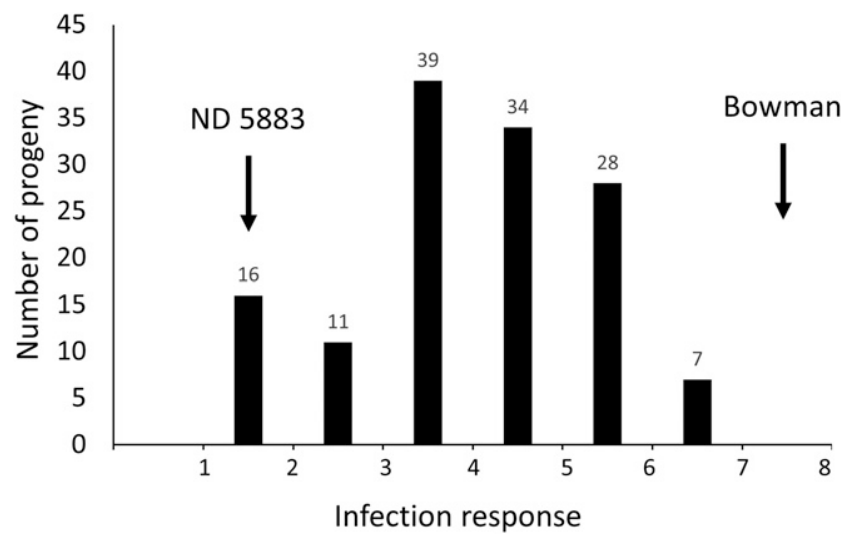

Fig. 1. Frequency distributions for the mean of the most common infection response (IR) to spot blotch among the recombinant inbred lines derived from cross between Bowman and ND5883 at the seedling stage. The IR of each barley plant was rated using the 1 to 9 rating scale of Fetch and Steffenson (1999).

\section{RESULTS}

Phenotype data. Bowman and ND5883 exhibited low IRs ( 1 to 3 ) and high IRs (7 to 9) when infected with the pathotype 1 isolate ND85F of Bipolaris sorokiniana. Conversely, they exhibited high IRs ( 7 to 9) and low IRs (1 to 3 ) when infected with the pathotype 2 isolate ND90Pr of Bipolaris sorokiniana. The distribution pattern of the RIL population to pathotype 1 was continuous (Fig. 1). With pathotype 2 , the RIL population segregated into 67 resistant and 61 susceptible, fitting a $1: 1$ ratio $\left(\chi^{2}=0.28, P=0.60\right)$ and indicating a single gene locus controlling susceptibility and resistance. The recessive resistance allele was previously designated as Rcs6 (Bilgic et al. 2006), and the dominant susceptibility allele was designated as $S \operatorname{cs} 6$ (Leng et al. 2018).

Evaluation of Bowman and ND5883 along with standard barley differential lines carrying known PM resistance genes using the 50 Blumeria graminis f. sp. hordei isolates revealed that no specific PM resistance genes were present in Bowman, whereas Mla8 and Mlk1 were identified in ND5883 (Table 1). Among the 50 Blumeria graminis f. sp. hordei isolates tested, Race I showed avirulence on ND5883 with a rating of 0,0 to 1 , or 1 (with hypersensitive flecks) and virulence on Bowman with a rating of 4 , and thus it was selected to evaluate 133 of the 138 RILs derived from the cross between Bowman and ND5883. The 133 RILs segregated in a 1:1 ratio (72 resistant, 61 susceptible) $\left(\chi^{2}=0.91\right.$; $P=0.34$ ), suggesting that a single gene (Mla8) controls the resistance to PM in ND5883.

Sequence reads from the mapping population derived from the Bowman $\times$ ND5883 cross. In the BGI500 sequencing platform, 712.05 and 708.20 million 100-bp reads were generated from Bowman and ND5883, respectively. A total of 389.77 million 150-bp reads were generated from the 138 RILs with a highthroughput sequencer. The number of reads per RIL ranged from 9,921 to 4,946,336 (Supplementary Table S2). All sequence reads generated from the population were submitted to the Sequence Read Archive section of the NCBI (accession no. PRJNA514287).

Identification of SNP markers and construction of linkage map. The TASSEL-GBS pipeline was used to identify the SNP markers in the mapping population. The sequence reads were first filtered to keep only those uniquely mapped to the reference genome, leading to $70.03 \%$ of the 389.76 million reads left for SNP discovery and genotype calling. A total of 5,215 SNP markers were identified according to the following parameters: read depth $>3$, minor allele frequency $>0.05$, and missing data $<20 \%$ (Supplementary Table S3). SNP markers were named based on their physical positions on the pseudomolecules corresponding to seven barley chromosomes (1H to $7 \mathrm{H})$ (Mascher et al. 2017). For example, 1H_51926 represents a SNP marker located at position $51926 \mathrm{bp}$ on pseudomolecule of $1 \mathrm{H}$.

The 5,215 SNP markers were analyzed in MapDisto, and only 4,905 high-confidence SNP markers were left for construction of linkage maps. After removal of the cosegregating markers, 852 unique SNP markers were used in the final construction of the genetic map. Nine linkage groups were generated, with the number of markers per group ranging from 14 to 201 (Supplementary Fig. S1; Supplementary Table S3).

Mapping of the gene and QTLs for susceptibility to SB and the gene for resistance to PM. As expected, the gene (Scs6) for susceptibility to the pathotype 2 isolate ND90Pr, contributed by Bowman, was mapped on the short arm of chromosome $1 \mathrm{H}$ (Fig. 2A). The gene (Mla8) for PM resistance was also mapped to the short arm of chromosome $1 \mathrm{H}$, which was tightly linked to Scs6 (Fig. 2A). The distance between $S c s 6$ and Mla 8 was $0.4 \mathrm{cM}$.

QTL analysis identified two QTLs (QScs-1H-P1 and QScs-7H-P2) for susceptibility to the pathotype 1 isolate ND85F at the seedling stage, both contributed by ND5883 and mapped on chromosome $1 \mathrm{H}$ and $7 \mathrm{H}$, respectively (Fig. 2). QScs- $1 \mathrm{H}-\mathrm{Pl}$ peaked at marker $1 \mathrm{H}_{-}$ 256259151, flanked by 1H_20693748 and 1H_486185365, and 

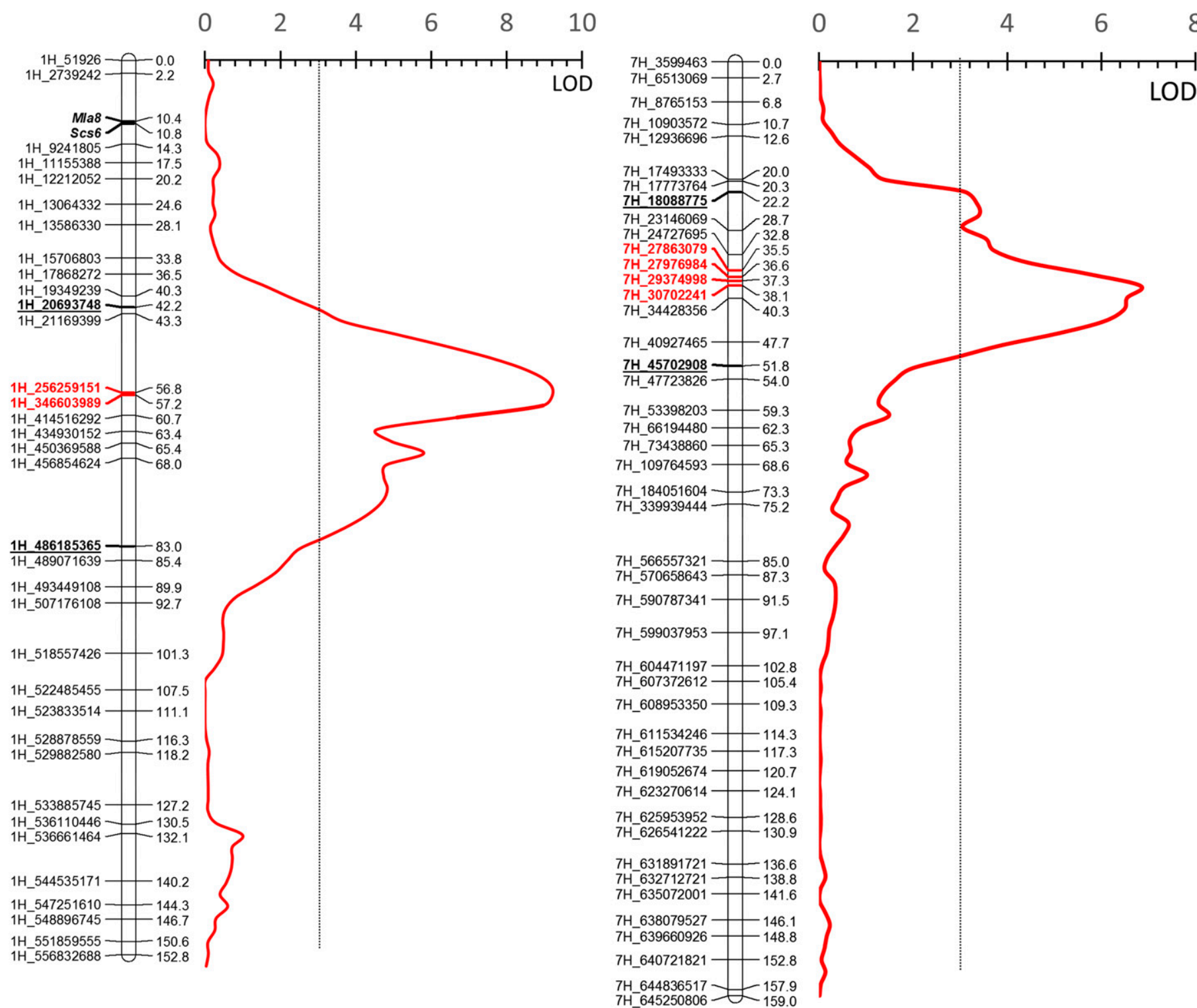

Fig. 2. Regions of linkage maps for $\mathbf{A}$, chromosome $1 \mathrm{H}$ and $\mathbf{B}$, chromosome $7 \mathrm{H}$ harboring Mla 8 for powdery mildew resistance, Scs6 and quantitative trait loci (QTLs) for spot blotch susceptibility detected in the mapping population derived from the cross between barley line ND5883 and cultivar Bowman. Mla8 was identified in ND5883, and Scs6 was detected in Bowman. Both QTLs on 1H and 7H for spot blotch susceptibility were derived from the susceptible barley parent ND5883. The centimorgan (cM) distances between marker loci and the positions of marker loci are on the right and left sides of the linkage maps, respectively. The logarithm of the odds (LOD) significance threshold 3.0 is represented by a vertical dotted line. The markers that are most closely linked to the QTLs are marked in dark gray (red). The markers flanking the QTL region are underlined and bold.

TABLE 1. Infection response arrays of 4 barley genotypes to 10 selected Blumeria graminis f. sp. hordei isolates

\begin{tabular}{|c|c|c|c|c|c|c|c|c|c|c|c|}
\hline \multirow{3}{*}{ Barley genotype } & \multirow{3}{*}{ Genes } & \multicolumn{10}{|c|}{ Isolate } \\
\hline & & $\mathrm{GH}^{\mathrm{a}}$ & $3-33$ & Z-6 & EmA30 & 120 & $\mathrm{~J}-462$ & Race I & 65 & KM18 & MN-B \\
\hline & & $A^{b}$ & $\mathrm{CH}$ & $\mathrm{CZ}$ & DK & G & ISR & JAP & JAR & SW & USA \\
\hline Bowman & None & 4 & 4 & 4 & 4 & 4 & 4 & 4 & 4 & 4 & 4 \\
\hline Pallas $^{\mathrm{d}}$ & Mla8 & 4 & 4 & 4 & 4 & 4 & 4 & $0-1$ & 4 & 4 & 4 \\
\hline Abee (selection) $)^{\mathrm{d}}$ & Mlk1 & 4 & 2 & 2 & 2 & 2 & 4 & 2 & 4 & 4 & 4 \\
\hline
\end{tabular}

a Isolate name. The origin and collection year of the isolate are indicated under the isolate name. Virulence and avirulence arrays of the Blumeria graminis f. sp. hordei isolates to 35 standard barley differential genotypes are shown in Dreiseitl (2019).

b Country where the isolate was collected: A, Australia; CH, China; CZ, Czech Republic; DK, Denmark; G, Germany; ISR, Israel; JAP, Japan; JAR, Republic of South Africa; SW, Sweden; USA, United States of America (Minnesota).

c Year when the isolate was collected.

d Standard differential barley genotypes used to postulate the genes in ND5883. 
explained $27 \%$ of the total phenotypic variation, whereas $Q S c s$ $7 \mathrm{H}-\mathrm{Pl}$ peaked at marker 7H_30702241, flanked by 7H_18088775 and 7H_45702908, and explained $20.8 \%$ of the variation (Table 2).

Effects of individual and combined QTLs on SB susceptibility were further investigated by grouping the RILs according to genotypes of marker loci, 1H_256259151 and 7H_30702241, closely linked to the two QTLs on $1 \mathrm{H}$ and $7 \mathrm{H}$, respectively. RILs carrying one or both susceptibility QTL alleles showed a significantly higher IR than those with resistance alleles (Fig. 3). The result indicated that both QTLs increased susceptibility to SB, and their effects were additive.

\section{DISCUSSION}

A previous study identified a single gene $(R \operatorname{cs} \sigma)$ for resistance to pathotype 2 isolate ND90Pr in a DH population derived from the Calicuchima-sib/Bowman-BC cross (Bilgic et al. 2006). The Rcs6 allele contributed by Calicuchima-sib was mapped on the short arm of chromosome $1 \mathrm{H}$ and effectively confers both seedling and adult plant resistance (Bilgic et al. 2006). Using the same $\mathrm{DH}$ population from the Calicuchima-sib/Bowman-BC cross and a large population of $\mathrm{F}_{2}$ individuals from the Bowman/ND5883 cross, we showed that $R \operatorname{cs} 6$ is a recessive allele, whereas the corresponding allele $(\operatorname{ses} 6)$ at the same locus is dominant and responsible for susceptibility to SB in Bowman (Leng et al. 2018). Scs6/Rcs6 was finely mapped to the PM resistance Mla locus within a $125-\mathrm{kb}$ region of chromosome $1 \mathrm{H}$ of Morex (Leng et al. 2018). Among the six markers cosegregating with $S c s 6$, four contained sequences encoding NBS-LRR proteins, which led us to hypothesize that $S \operatorname{cs} 6$ may represent an Mla allele, conferring resistance to PM but susceptibility to SB (Leng et al. 2018). In the present study, we showed that Scs6 and Mla 8 were not cosegregating, although they were tightly linked together on chromosome $1 \mathrm{H}$, suggesting that Scs6 and Mla8 are not allelic. However, considering the fact that the genome structure of the Mla locus is complex and highly diversified across different barley genotypes, and there are multiple copies of Mla alleles at this locus (Seeholzer et al. 2010; Wei et al. 1999, 2002; Y. Leng and S. Zhong, unpublished data), the possibility that Scs6 represents one of the Mla homologs at the Mla locus cannot be ruled out.

Using a DH population derived from the Steptoe and Morex (S/M) cross, Steffenson et al. (1996) detected one major gene (Rcs5) for seedling resistance and two QTLs for adult plant resistance to SB caused by pathotype 1 isolate ND85F, with the major effect QTL on chromosome $1 \mathrm{H}$ explaining $62 \%$ of the phenotypic variance and the minor effect QTL mapping to the Rcs5 region on chromosome $7 \mathrm{H}$ explaining $9 \%$ of the phenotypic variance. Later, Bilgic et al. (2005) confirmed these two QTLs by using the same S/M population and designated them as Rcs-qtl-1H-6-7 and Rcs-qtl$7 H-2-4$, respectively. In the present study, we detected two QTLs (QScs-1H-Pl and $Q S c s-7 H-P l$ ) for susceptibility to SB caused by $\mathrm{ND} 85 \mathrm{~F}$ at the seedling stage in the RIL population derived from the Bowman/ND5883 cross. The 7H QTL, QScs-7H-Pl contributed by ND5883, was mapped at the same region as Rcs5 (Bilgic et al. 2005; Steffenson et al. 1996), suggesting that $Q S c s-7 H-P 1, R c s-q t l-7 H-2-$ 4 , and $R \operatorname{cs} 5$ may be allelic or closely linked together at the same locus. Recently, Ameen (2019) showed that Rcs5 is a recessive allele carried by Morex, whereas the corresponding susceptibility allele carried by Steptoe is dominant, which contains two functional genes ( $R b s 1$ and $R b s 2$ ) controlling the susceptibility to pathotype 1 isolate ND85F. The peak marker (1H_256259151) of QScs-7H-P1 is homologous to HvWakl (HORVU7Hr1G020700), which is only $56 \mathrm{~kb}$ from the susceptibility gene ( $S b s 1$ ) at the Rcs5 locus (Ameen 2019). It is possible that QScs-7H-Pl contributed by ND5883 contains the same susceptibility genes as Steptoe, but PCR amplification and sequencing of $R b s 1$ and $R b s 2$ from ND5883 should be done to confirm this hypothesis. The 1H QTL, QScs-1H$P 1$, also contributed by ND5883, was mapped to the same region as Rcs-qtl-1H-6-7 in Morex (Bilgic et al. 2005). However, it is not known whether $Q S c s-1 H-P 1$ and $R c s-q t l-1 H-6-7$ are allelic to each other or closely linked at the same locus because Rcs-qtl-1H-6-7 conferred adult plant resistance to $\mathrm{SB}$ in the $\mathrm{S} / \mathrm{M}$ population, whereas $Q S c s-1 H-P 1$ controlling SB susceptibility was detected at the seedling stage in the Bowman/ND5883 population. Additional studies are needed to determine whether $Q S c s-1 H$ - $P 1$ also controls the susceptibility at the adult plant stage.

In a genetic study with two other $\mathrm{DH}$ populations derived from crosses of Harrington/Morex (H/M) and Dicktoo/Morex (D/M), Bilgic et al. (2005) failed to detect the 1H QTL (Rcs-qtl-1H-6-7) originally identified by Steffenson et al. (1996) in the S/M population although all three mapping populations (H/M, D/M, and $\mathrm{S} / \mathrm{M}$ ) shared the same resistant parent Morex. The reason that $R c s-q t l-1 H-6-7$ was detected in $\mathrm{S} / \mathrm{M}$ but not in $\mathrm{H} / \mathrm{M}$ and $\mathrm{D} / \mathrm{M}$ could not be well explained at that time because of the assumption that SB resistance is controlled by dominant gene alleles. With more evidence indicating that the barley-Bipolaris sorokiniana interactions fall mostly under the inverse gene-for-gene interaction

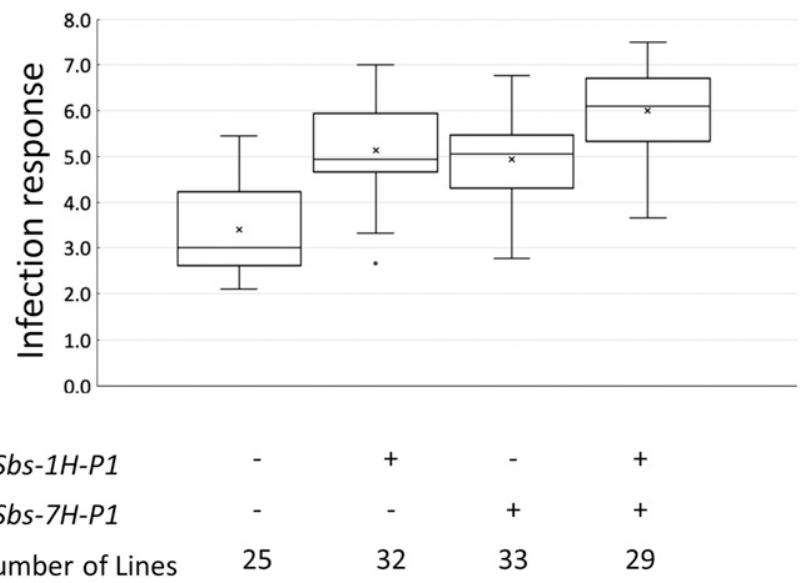

Fig. 3. Box plot distributions of recombinant inbred lines according to allele combinations at markers associated with quantitative trait loci (QTLs) for susceptibility to spot blotch caused by the isolate ND85F of Bipolaris sorokiniana in the mapping population. The infection response represents the mean disease ratings based on the 1 to 9 rating scale of Fetch and Steffenson (1999). Medians are indicated by solid lines, $\times$ represents mean, the dot represents an outlier, + represents presence of the QTL, and - represents absence of the QTL. The number of RILs for each group is also indicated.

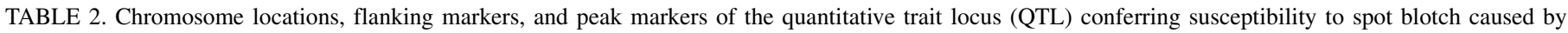
isolate ND85F of Bipolaris sorokiniana at the seedling stage

\begin{tabular}{|c|c|c|c|c|c|c|}
\hline Chromosome & QTL & Marker interval & Peak marker & LOD value ${ }^{a}$ & $R^{2}$ value $^{\mathrm{b}}$ & $\operatorname{Add}^{\mathrm{c}}$ \\
\hline $1 \mathrm{H}$ & $Q S b s-1 H-P 1$ & 1H_20693748-1H_486185365 & 1H_256259151 & 9.224 & 0.270 & -0.712 \\
\hline $7 \mathrm{H}$ & $Q S b s-7 H-P 1$ & 7H_18088775-7H_45702908 & 7H_30702241 & 6.841 & 0.208 & -0.589 \\
\hline
\end{tabular}

a Logarithm of the odds (LOD) value was calculated through a 1,000-iteration permutation test at the 0.01 level of probability.

b $R^{2}$ value represents the percentage of phenotypic variance explained by the QTL.

c Negative value indicates that the ND5883 allele increases the trait (disease severity) value relative to the Bowman allele. 
scenario (Wolpert et al. 2002), where disease susceptibility is induced by the interaction between a dominant susceptibility gene in the plant and the effector produced by the pathogen (Ameen 2019; Leng et al. 2018; Singh et al. 2014; Valjavec-Gratian 1996; Valjavec-Gratian and Steffenson 1997a), it is not a surprise that a resistance QTL allele was detected in one $\mathrm{DH}$ population but not in other DH populations derived from the same resistant parent. In the S/M population, Steptoe contributed the dominant susceptibility allele (Rcs-qtl-1H-6-7S), whereas Morex contributed the recessive resistance allele (Rcs-qtl-1H-6-7s) at the locus, thus the QTL could be detected regardless of alleles (Bilgic et al. 2005; Steffenson et al. 1996). In the H/M population, if both Harrington and Morex carried the recessive resistance allele (Rcs-qtl-1H-6-7s) at the locus, this QTL would not be detected at the locus in this population, as observed by Bilgic et al. (2005). The same is true for the D/M population because Dicktoo and Morex carried the same recessive resistance allele (Rcs-qtl-1H-6-7s). However, Bilgic et al. (2005) detected several other different resistance QTLs for SB resistance in $\mathrm{H} / \mathrm{M}$ and $\mathrm{D} / \mathrm{M}$ populations because the susceptible parents Harrington and Dicktoo carried the corresponding susceptibility alleles for the fungal isolate ND85F. We suggest that dominant and recessive relationship of resistance and susceptibility for SB should be considered during QTL analysis, and the dominant alleles of the loci should be designated whenever the relationship is known.

A number of genes or QTLs for SB resistance have been reported in barley, and they are distributed on all seven barley chromosomes (Berger et al. 2013; Bilgic et al. 2005, 2006; Bovill et al. 2010; Castro et al. 2012; Grewal et al. 2012; Wang et al. 2017, 2019; Zhou and Steffenson 2013). Some genes or QTLs are responsible for the seedling stage resistance and some control the resistance at the adult plant stage, whereas some others are effective for resistance throughout the whole growth stages. The majority of these genes or QTLs were detected by biparental mapping with DH and RIL populations or by genome-wide association studies, and thus the dominant/recessive relationship between alleles at each locus is not known. Considering that a resistance gene can be recessive (Ameen 2019; Leng et al. 2018) or dominant (Wang et al. 2019), further efforts are needed to determine which QTLs or genes confer susceptibility and which QTLs or genes control resistance to SB. This has practical significance in breeding program because susceptible dominant alleles should be removed to develop resistant cultivars, whereas resistance alleles should be selected no matter whether they are dominant or recessive.

In summary, we constructed a genetic map of barley with SNP markers generated by SBG and identified one major gene $(S \operatorname{cs} \sigma)$ and two QTLs (QScs-1H-P1 and $Q S c s-7 H-P 1)$ responsible for SB susceptibility to two different pathotype isolates in the population from a cross between Bowman and ND5883. We showed that the Scs6 gene was not the Mla8 gene, although it could be one of the other Mla homologs at the Mla locus. The 7H QTL, QScs-7H-P1, may be the same as the susceptible gene allele (rcs5) carrying $S b s 1$ and $S b s 2$ in Steptoe, whereas the 1H QTL, QScs-1H-P1, may represent a novel gene allele at the Rcs-qtl-1H-6-7 locus. Identification of genes or QTLs controlling susceptibility or resistance to SB and their closely linked DNA markers will facilitate the development of durable resistance to the disease by eliminating susceptible gene alleles and keeping resistance gene alleles.

\section{LITERATURE CITED}

Ameen, G. 2019. Cloning and characterization of rcs5, spot blotch resistance gene and pathogen induced nec3 gene involved in programmed cell death in barley. Ph.D. thesis, North Dakota State University, Fargo.

Ames, N., Dreiseitl, A., Steffenson, B. J., and Muehlbauer, G. J. 2015. Mining wild barley for powdery mildew resistance. Plant Pathol. 64:1396-1406.

Baker, B., Zambryski, P., Staskawicz, B., and Dinesh-Kumar, S. P. 1997. Signaling in plant-microbe interactions. Science 276:726-733.

Bayer, M. M., Rapazote-Flores, P., Ganal, M., Hedley, P. E., Macaulay, M., Plieske, J., Ramsay, L., Russell, J., Shaw, P. D., and Thomas, W. 2017.
Development and evaluation of a barley $50 \mathrm{k}$ iSelect SNP array. Front. Plant Sci. 8:1792.

Bengtsson, T., Åhman, I., Manninen, O., Reitan, L., Christerson, T., Due Jensen, J., Krusell, L., Jahoor, A., and Orabi, J. 2017. A novel QTL for powdery mildew resistance in nordic spring barley (Hordeum vulgare L. ssp. vulgare) revealed by genome-wide association study. Front. Plant Sci. 8:1954.

Berger, G. L., Liu, S., Hall, M. D., Brooks, W. S., Chao, S., Muehlbauer, G. J., Baik, B. K., Steffenson, B. J., and Griffey, C. A. 2013. Marker-trait associations in Virginia Tech winter barley identified using genome-wide mapping. Theor. Appl. Genet. 126:693-710.

Bilgic, H., Steffenson, B. J., and Hayes, P. 2005. Comprehensive genetic analyses reveal differential expression of spot blotch resistance in four populations of barley. Theor. Appl. Genet. 111:1238-1250.

Bilgic, H., Steffenson, B. J., and Hayes, P. M. 2006. Molecular mapping of loci conferring resistance to different pathotypes of the spot blotch pathogen in barley. Phytopathology 96:699-708.

Both, M., and Spanu, P. 2004. Blumeria graminis f. sp. hordei, an obligate pathogen of barley. Pages 202-218 in: Plant Pathogen Interactions. N. Talbot, ed. Blackwell Publishing, Oxford, UK.

Bovill, J., Lehmensiek, A., Sutherland, M. W., Platz, G. J., Usher, T., Franckowiak, J., and Mace, E. 2010. Mapping spot blotch resistance genes in four barley populations. Mol. Breed. 26:653-666.

Brown, J. K. M., and Rant, J. C. 2013. Fitness costs and trade-offs of disease resistance and their consequences for breeding arable crops. Plant Pathol. 62:83-95.

Büschges, R., Hollricher, K., Panstruga, R., et al. 1997. The barley Mlo gene: a novel control element of plant pathogen resistance. Cell 88:695-705.

Castro, A. J., Gamba, F., German, S., Gonzalez, S., Hayes, P. M., Pereyra, S., and Perez, C. 2012. Quantitative trait locus analysis of spot blotch and leaf rust resistance in the BCD47 Baronesse barley mapping population. Plant Breed. 131:258-266.

Chaure, P., Gurr, S. J., and Spanu, P. 2000. Stable transformation of Erysiphe graminis an obligate biotrophic pathogen of barley. Nat. Biotechnol. 18: 205-207.

Chen, W., Chen, H., Zheng, T., Yu, R., Terzaghi, W. B., Li, Z., Deng, X. W., $\mathrm{Xu}$, J., and He, H. 2014. Highly efficient genotyping of rice biparental populations by GoldenGate assays based on parental re-sequencing. Theor. Appl. Genet. 127:297-307.

Close, T. J., Bhat, P. R., Lonardi, S., Wu, Y., Rostoks, N., Ramsay, L., et al. 2009. Development and implementation of high-throughput SNP genotyping in barley. BMC Genomics 10:582.

Comadran, J., Kilian, B., Russell, J., Ramsay, L., Stein, N., Ganal, M., et al. 2012. Natural variation in a homolog of Antirrhinum CENTRORADIALIS contributed to spring growth habit and environmental adaptation in cultivated barley. Nat. Genet. 44:1388-1392.

Dreiseitl, A. 2011. Differences in powdery mildew epidemics in spring and winter barley based on 30-year variety trials. Ann. Appl. Biol. 159:49-57.

Dreiseitl, A. 2014. Pathogenic divergence of Central European and Australian populations of Blumeria graminis f. sp. hordei. Ann. Appl. Biol. 165: 364-372.

Dreiseitl, A. 2019. A novel resistance against powdery mildew found in winter barley cultivars. Plant Breed.: pbr.12730.

Dreiseitl, A., and Platz, G. 2012. Powdery mildew resistance genes in barley varieties grown in Australia. Crop Pasture Sci. 63:997-1006.

Fan, J. B., Oliphant, A., Shen, R., Kermani, B. G., Garcia, F., Gunderson, K. L., et al. 2003. Highly parallel SNP genotyping. Cold Spring Harb. Symp. Quant. Biol. 68:69-78.

Fetch, T. G., and Steffenson, B. J. 1999. Rating scales for assessing infection responses of barley infected with Cochliobolus sativus. Plant Dis. 83: 213-217.

Franckowiak, J. D., Foster, A. E., Pederson, V. D., and Pyler, R. E. 1985. Registration of 'Bowman' barley. Crop Sci. 25:883.

Ganal, M. W., Durstewitz, G., Polley, A., Berard, A., Buckler, E. S., Charcosset, A., Clarke, J. D., Graner, E. M., Hansen, M., Joets, J., Le Paslier, M. C., McMullen, M. D., Montalent, P., Rose, M., Schön, C. C., Sun, Q., Walter, H., Martin, O. C., and Falque, M. 2011. A large maize (Zea mays L.) SNP genotyping array: Development and germplasm genotyping, and genetic mapping to compare with the B73 reference genome. PLoS One 6:e28334.

Glaubitz, J. C., Casstevens, T. M., Lu, F., Harriman, J., Elshire, R. J., Sun, Q., and Buckler, E. S. 2014. TASSEL-GBS: A high capacity genotyping by sequencing analysis pipeline. PLoS One 9:e90346.

Grewal, T. S., Rossnagel, B. G., and Scoles, G. J. 2012. Mapping quantitative trait loci associated with spot blotch and net blotch resistance in a doubledhaploid barley population. Mol. Breed. 30:267-279.

Hiura, U., and Heta, H. 1955. Studies on the disease-resistance in barley. III. Further studies on the physiologic races of Erysiphe graminis hordei in Japan. Berichte des Ohara Instituts für landwirtschaftliche Biologie 10: 13-156. 
Jarosch, B., Kogel, K.-H., and Schaffrath, U. 1999. The ambivalence of the barley Mlo locus: Mutations conferring resistance against powdery mildew (Blumeria graminis f. sp. hordei) enhance susceptibility to the rice blast fungus Magnaporthe grisea. Mol. Plant-Microbe Interact. 12:508-514.

Joehanes, R., and Nelson, J. C. 2008. QGene 4.0, an extensible Java QTLanalysis platform. Bioinformatics 24:2788-2789.

Jørgensen, J. H., and Wolfe, M. 1994. Genetics of powdery mildew resistance in barley. Crit. Rev. Plant Sci. 13:97-119.

Kølster, P., Munk, L., Stølen, O., and Løhde, J. 1986. Near-isogenic barley lines with genes for resistance to powdery mildew. Crop Sci. 26:903-907.

Kumar, J., Hückelhoven, R., Beckhove, U., Nagarajan, S., and Kogel, K.-H. 2001. A compromised Mlo pathway affects the response of barley to the necrotrophic fungus Bipolaris sorokiniana (Teleomorph: Cochliobolus sativus) and its toxins. Phytopathology 91:127-133.

Kumar, J., Schafer, P., Huckelhoven, R., et al. 2002. Bipolaris sorokiniana, a cereal pathogen of global concern: Cytological and molecular approaches towards better control. Mol. Plant Pathol. 3:185-195.

Kumar, S., Banks, T. W., and Cloutier, S. 2012. SNP discovery through nextgeneration sequencing and its applications. Int. J. Plant Genomics 2012:831460.

Kusch, S., and Panstruga, R. 2017. mlo-Based resistance: An apparently universal "weapon" to defeat powdery mildew disease. Mol. Plant-Microbe Interact. 30:179-189.

Leng, Y., Wang, R., Ali, S., Zhao, M., and Zhong, S. 2016. Sources and genetics of spot blotch resistance to a new pathotype of Cochliobolus sativus in the USDA Small Grains Collection. Plant Dis. 100:1988-1993.

Leng, Y., Wu, C., Liu, Z., Friesen, T. L., Rasmussen, J. B., and Zhong, S. 2011. RNA-mediated gene silencing in the cereal fungal pathogen Cochliobolus sativus. Mol. Plant Pathol. 12:289-298.

Leng, Y., Zhao, M., Wang, R., Steffenson, B. J., Brueggeman, R. S., and Zhong, S. 2018. The gene conferring susceptibility to spot blotch caused by Cochliobolus sativus is located at the Mla locus in barley cultivar Bowman. Theor. Appl. Genet. 131:1531-1539.

Leng, Y., and Zhong, S. 2012. Sfp-type 4-phosphopantetheinyl transferase is required for lysine synthesis, tolerance to oxidative stress and virulence in the plant pathogenic fungus Cochliobolus sativus. Mol. Plant Pathol. 13:375-387.

Leng, Y. Q., and Zhong, S. B. 2015. The role of mitogen-activated protein (MAP) kinase signaling components in the fungal development, stress response and virulence of the fungal cereal pathogen Bipolaris sorokiniana. PLoS ONE 10:e0128291.

Liu, H., Bayer, M., Druka, A., Russell, J. R., Hackett, C. A., Poland, J., Ramsay, L., Hedley, P. E., and Waugh, R. 2014. An evaluation of genotyping by sequencing (GBS) to map the breviaristatum-e (ari-e) locus in cultivated barley. BMC Genomics 15:1-11.

Lorieux, M. 2012. MapDisto: Fast and efficient computation of genetic linkage maps. Mol. Breed. 30:1231-1235.

Mascher, M., Gundlach, H., Himmelbach, A., Beier, S., Twardziok, S. O., Wicker, T., Radchuk, V., Dockter, C., Hedley, P. E., Russell, J., Bayer, M., Ramsay, L., Liu, H., Haberer, G., Zhang, X. Q., Zhang, Q., Barrero, R. A., Li, L., Taudien, S., Groth, M., Felder, M., Hastie, A., Simkova, H., Stankova, H., Vrana, J., Chan, S., Munoz-Amatriain, M., Ounit, R., Wanamaker, S., Bolser, D., Colmsee, C., Schmutzer, T., Aliyeva-Schnorr, L., Grasso, S., Tanskanen, J., Chailyan, A., Sampath, D., Heavens, D., Clissold, L., Cao, S., Chapman, B., Dai, F., Han, Y., Li, H., Li, X., Lin, C., McCooke, J. K., Tan, C., Wang, P., Wang, S., Yin, S., Zhou, G., Poland, J. A., Bellgard, M. I., Borisjuk, L., Houben, A., Dolezel, J., Ayling, S., Lonardi, S., Kersey, P., Langridge, P., Muehlbauer, G. J., Clark, M. D., Caccamo, M., Schulman, A. H., Mayer, K. F. X., Platzer, M., Close, T. J., Scholz, U., Hansson, M., Zhang, G., Braumann, I., Spannagl, M., Li, C., Waugh, R., and Stein, N. 2017. A chromosome conformation capture ordered sequence of the barley genome. Nature 544:427-433.

Mathre, D. E. 1997. Compendium of Barley Diseases, 2nd ed. American Phytopathological Society Press, St. Paul, MN.

McGrann, G. R. D., Stavrinides, A., Russell, J., Corbitt, M. M., Booth, A., Chartrain, L., Thomas, W. T. B., and Brown, J. K. M. 2014. A trade off between mlo resistance to powdery mildew and increased susceptibility of barley to a newly important disease, Ramularia leaf spot. J. Exp. Bot. 65:1025-1037.

Monat, C., Padmarasu, S., Lux, T., Wicker, T., Gundlach, H., Himmelbach, A., Ens, J., Li, C., Muehlbauer, G. J., Schulman, A. H., Waugh, R., Braumann, I., Pozniak, C., Scholz, U., Mayer, K. F. X., Spannagl, M., Stein, N., and Mascher, M. 2019. TRITEX: chromosome-scale sequence assembly of Triticeae genomes with open-source tools. bioRxiv 631648.

Murray, G. M., and Brennan, J. P. 2010. Estimating disease losses to the Australian barley industry. Australas. Plant Pathol. 39:85-96.
Poland, J. A., Brown, P. J., Sorrells, M. E., and Jannink, J. L. 2012. Development of high-density genetic maps for barley and wheat using a novel two-enzyme genotyping-by-sequencing approach. PLoS One 7:e32253.

Saintenac, C., Jiang, D., Wang, S., and Akhunov, E. 2013. Sequence-based mapping of the polyploid wheat genome. G3 Genes Genomes Genet. 3: 1105-1114.

Schönfeld, M., Ragni, A., Fischbeck, G., and Jahoor, A. 1996. RFLP mapping of three new loci for resistance genes to powdery mildew (Erysiphe graminis f. sp. hordei) in barley. Theor. Appl. Genet. 93:48-56.

Seeholzer, S., Tsuchimatsu, T., Jordan, T., Bieri, S., Pajonk, S., Yang, W., Jahoor, A., Shimizu, K. K., Keller, B., and Schulze-Lefert, P. 2010. Diversity at the Mla powdery mildew resistance locus from cultivated barley reveals sites of positive selection. Mol. Plant-Microbe Interact. 23:497-509.

Singh, S., Singh, H., Sharma, A., Meeta, M., Singh, B., Joshi, N., Grover, P., Al-Yassin, A., and Kumar, S. 2014. Inheritance of spot blotch resistance in barley (Hordeum vulgare L.). Can. J. Plant Sci. 94:1203-1209.

Steffenson, B. J., Hayes, P. M., and Kleinhofs, A. 1996. Genetics of seedling and adult plant resistance to net blotch (Pyrenophora teres $\mathrm{f}$. teres) and spot blotch (Cochliobolus sativus) in barley. Theor. Appl. Genet. 92:552-558.

Torp, J., Jensen, H. P., and Jørgensen, J. H. 1978. Powdery mildew resistance genes in 106 Northwest European spring barley cultivars. Pages 75-102 in: Royal Veterinary and Agricultural University. Yearbook 1978. Royal Veterinary and Agricultural College, Copenhagen, Denmark.

Valjavec-Gratian, M. 1996. Genetics of resistance and virulence in the Hordeum vulgare: Cochliobolus sativus pathosystem. Ph.D. dissert. North Dakota State University, Fargo.

Valjavec-Gratian, M., and Steffenson, B. J. 1997a. Genetics of virulence in Cochliobolus sativus and resistance in barley. Phytopathology 87:1140-1143.

Valjavec-Gratian, M., and Steffenson, B. J. 1997b. Pathotypes of Cochliobolus sativus on barley in North Dakota. Plant Dis. 81:1275-1278.

Voorrips, R. E. 2002. MapChart: Software for the graphical presentation of linkage maps and QTLs. J. Hered. 93:77-78.

Wang, R., Leng, Y., Ali, S., Wang, M., and Zhong, S. 2017. Genome-wide association mapping of spot blotch resistance to three different pathotypes of Cochliobolus sativus in the USDA barley core collection. Mol. Breed. 37:44.

Wang, R., Leng, Y., Shrestha, S., and Zhong, S. 2016. Coordinated and independent functions of velvet-complex genes in fungal development and virulence of the fungal cereal pathogen Cochliobolus sativus. Fungal Biol. 120:948-960.

Wang, R., Leng, Y., Zhao, M., and Zhong, S. 2019. Fine mapping of a dominant gene conferring resistance to spot blotch caused by a new pathotype of Bipolaris sorokiniana in barley. Theor. Appl. Genet. 132:41-51.

Wang, R., Leng, Y., and Zhong, S. 2015. The regulatory gene VosA affects conidiogenesis and is involved in virulence of the fungal cereal pathogen Cochliobolus sativus. Fungal Biol. 119:884-900.

Wang, S., Wong, D., Forrest, K., Allen, A., Chao, S., Huang, B. E., et al. 2014. Characterization of polyploid wheat genomic diversity using a high-density 90,000 single nucleotide polymorphism array. Plant Biotechnol. J. 12: 787-796.

Wei, F., Gobelman-Werner, K., Morroll, S. M., Kurth, J., Mao, L., Wing, R., et al. 1999. The Mla (powdery mildew) resistance cluster is associated with three NBS-LRR gene families and suppressed recombination within a 240-kb DNA interval on chromosome 5S (1HS) of barley. Genetics 153: 1929-1948.

Wei, F., Wing, R. A., and Wise, R. P. 2002. Genome dynamics and evolution of the Mla (powdery mildew) resistance locus in barley. Plant Cell 14: 1903-1917.

Wilcoxson, R. D., Rasmusson, D. C., and Miles, M. R. 1990. Development of barley resistant to spot blotch and genetics of resistance. Plant Dis. 74: 207-210.

Winfield, M. O., Allen, A. M., Burridge, A. J., Barker, G. L., Benbow, H. R., Wilkinson, P. A., et al. 2016. High-density SNP genotyping array for hexaploid wheat and its secondary and tertiary gene pool. Plant Biotechnol. J. 14:1195-1206.

Wolpert, T. J., Dunkle, L. D., and Ciuffetti, L. M. 2002. Host-selective toxins and avirulence determinants: what's in a name? Annu. Rev. Phytopathol. 40:251-285.

Zhong, S., and Steffenson, B. J. 2001. Virulence and molecular diversity in Cochliobolus sativus. Phytopathology 91:469-476.

Zhou, H., and Steffenson, B. J. 2013. Genome-wide association mapping reveals genetic architecture of durable spot blotch resistance in US barley breeding germplasm. Mol. Breed. 32:139-154. 